DOI: $10.12731 / 2070-7568-2020-2-133-150$

УДК 338.242.2

\title{
КОНЦЕПТУАЛЬНАЯ МОДЕЛЬ ОЦЕНКИ ЭФФЕКТИВНОСТИ ГЧП-ПРОЕКТОВ
}

\author{
Мажарова Л.А.
}

В статье представлена авторская модель оценки государственными органами эффективности ГЧП-проектов.

Состояние вопроса: актуальность темы исследования обусловлена тем, что ускорение темпов привлечения средств, расширение набора возможных вариантов ГЧП-соглашений, увеличение числа инновационных проектов усиливают проблему разработки комплексных критериев эффективности ГЧП. Однако большинство современных исследований носят достаточно узкий характер и рассматривают только один из аспектов феномена ГЧП. В этой связи, иелью представленного исследования является разработка концептуальной модели оценки эффективности ГЧП-проектов.

Материалы и методы исследования: материалами исследования стали труды отечественных и зарубежнных авторов, нормативная и статистическая информация в области ГЧП. Были применены методы логического анализа и синтеза, индукиии и дедукиии.

Результаты исследования: автором была разработана модель, включающая четыре этапа оченки эффективности: 1) оченку достижимости и иелесообразности проекта; 2) сравнительную оценку эффективности ГЧП-проекта; 3) оценку социильной эффективности; 4) итоговую оценку экономической эффективности ГЧП-проекта. Предложенная модель ориентирована на то, чтобы учесть в окончательном варианте проекта интересы не только государства, но и бизнеса, что расширит круг потенциальных частных партнеров. Это определяет ее практическую значимость как при разработке нормативных актов, так и для обоснования эффективности отдельных ГЧП проектов. 
Ключевые слова: государственно-частное партнерство; экономическая эффективность; сочиальная эффективность; государственное управление; коммерческие организаџии.

\section{CONCEPTUAL MODEL FOR EVALUATING THE EFFECTIVENESS OF PPP PROJECTS}

\section{Mazharova L.A.}

The article presents the author's model for evaluating the effectiveness of PPP projects by government agencies.

Status of the issue: the relevance of the research topic due to the fact that the acceleration of raising funds, expanding the set of possible variants of PPP agreements, an increase in the number of innovative projects enhance the problem of the development of integrated criteria of efficiency of a PPP. However, the majority of modern research is rather narrow and considers only one of the aspects of the PPP phenomenon in this regard, the purpose of this research is to develop a conceptual model for evaluating the effectiveness of PPP projects.

Materials and methods of research: the research materials were the works of domestic and foreign authors, normative and statistical information in the field of PPP. Methods of logical analysis and synthesis, induction and deduction were applied.

Research results: the author has developed a model that includes four stages of evaluating the effectiveness:1) assessment of the project's feasibility and feasibility; 2) comparative assessment of the PPP project's effectiveness; 3) assessment of social efficiency; 4) final assessment of the PPP project's economic efficiency. The proposed model is aimed at taking into account the interests of not only the state, but also business in the final version of the project, which will expand the range of potential private partners, which determines its practical significance both in the development of regulations and for justifying the effectiveness of individual PPP projects.

Keywords: public-private partnership; economic efficiency; social efficiency; public administration; businesses. 


\section{Введение}

В современном мире государственно-частное партнерство (ГЧП) является распространенным и признанно действенным механизмом, позволяющим решить такие стратегические проблемы национальной экономики как:

- недостаточность бюджетных средств для обеспечения стабильного развития экономики и высокого уровня жизни населения;

- стимулирование конкуренции в социально значимых отраслях:

- объединение кадровых, технологических, финансовых ресурсов государства и частного сектора экономики, достижение синергетического эффекта;

- обеспечение паритета в развитии регионов и т.д. [более подробно см. 1].

Наша страна не является исключением: российская история ГЧП берет начало в XVII в., когда добыча руды и пушнины отдавалась в концессии иностранным предпринимателям [2, с. 460]. Развитие механизмов государственно-частного партнерства в современном понимании началось в 1990-е гг, а «поворотным моментом» стало принятие в 2015 году Федерального закона «О государственно-частном партнерстве, муниципально-частном партнерстве в Российской Федерации и внесении изменений в отдельные законодательные акты Российской Федерации» № 224-Ф3 [3]. Об активном развитии ГЧП свидетельствует тот факт, что количество одновременно реализуемых проектов за последние 10 лет возросло более чем в 15 раз (см. рис. 1).

Кроме того, необходимо отметить, что государственно-частное партнерство активно развивается в различных сферах (см. рис. 2): лидером по числу проектов является коммунально-энергетическая сфера, что соответствует основной декларируемой государством цели государственно-частного партнерства - развития системы предоставление качественных общественных благ. [более подробно см. 5, 6]. 


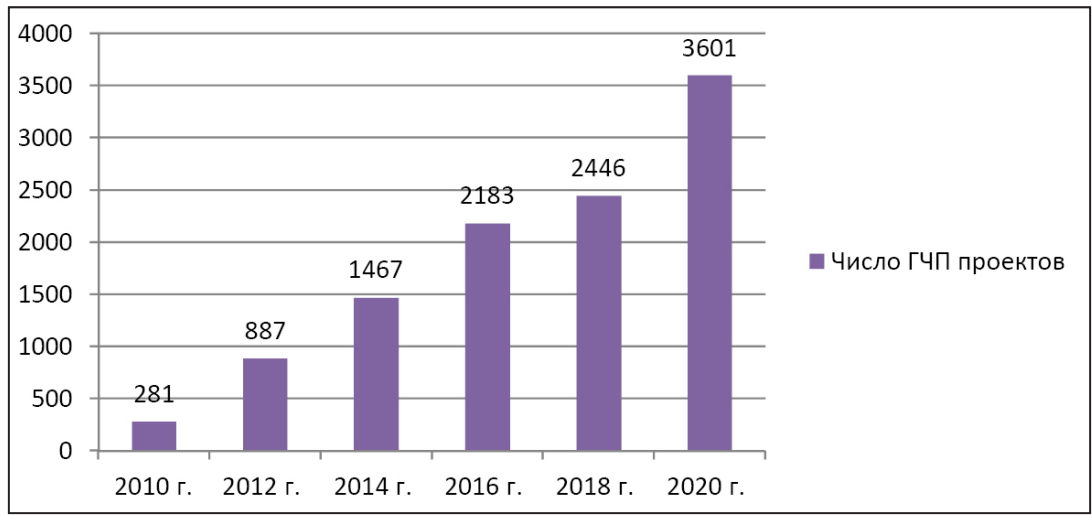

Рис. 1. Количество реализуемых ГЧП проектов 2010-2020 гг. Источник: [4]

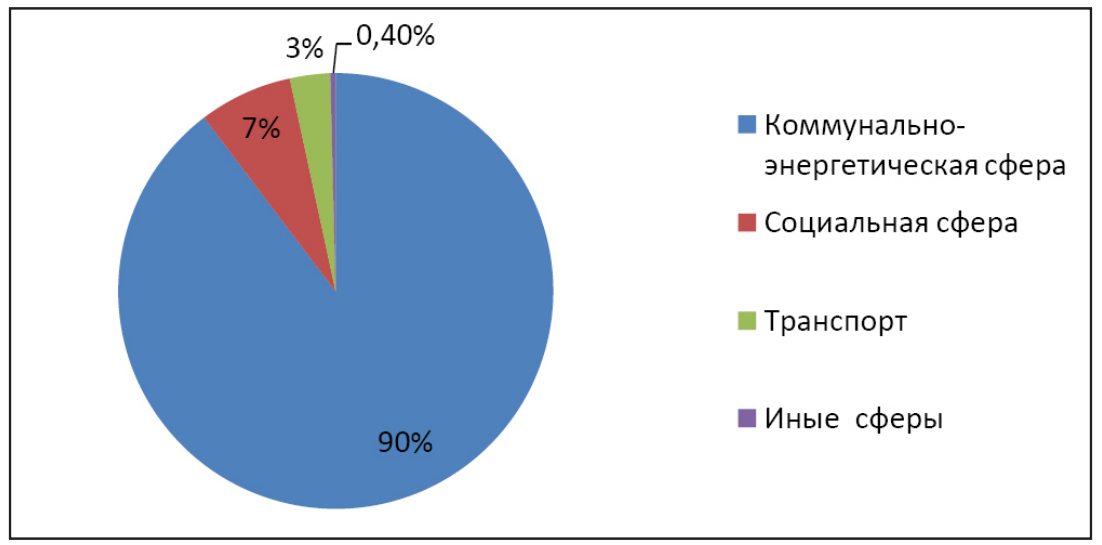

Рис. 2. Распределение количества ГЧП проектов по сферам по данным на начало 2019 г. Источник: [4]

Однако ускорение темпов привлечения средств, расширение набора возможных вариантов ГЧП-соглашений, увеличение числа инновационных проектов делают актуальной проблему разработки комплексных критериев эффективности ГЧП.

Необходимо отметить, что, несмотря на значительное количество научных исследований, посвященных ГЧП, большинство из них носят достаточно узкий характер и рассматривают только один из 
аспектов феномена ГЧП и, соответственно, ограниченно оценивают его эффективность. Так, можно выделить направление изучения ГЧП как юридического феномена, и соответственно, рассмотрение проблемы эффективности в контексте устранения пробелов законодательства [более подробно см. 7]. Существует также социальноэкономический подход, который рассматривает ГЧП в контексте регионального развития и не отделяет его эффективность от эффективности государственной или муниципальной политики [более подробно см. 8]. Имеет место собственно экономический подход, отраженный как в научных исследованиях [более подробно см. 4, 9], так и в нормативных актах РФ $[10,11]$, который подробно рассматривает экономическую (финансовую) эффективность ГЧП-проектов, но дает только общие рекомендации по оценке социальных эффектов. Аналогичная ситуация наблюдается и у зарубежных авторов. В исследованиях, в том числе инициированных государственными или международными организациями, авторы анализируют экономическую составляющую и, соответственно, эффективность [12, 13] либо изучают роль ГЧП и соответственно, его эффективность в отдельном территориальном [6] или отраслевом сегменте [14].

В связи с изложенным выше, целью представленного исследования является разработка концептуальной модели комплексной оценки эффективности ГЧП-проектов.

Задачами исследования, соответственно, являются:

- анализ существующих методик оценки эффективности ГЧПпроектов с целью выявления их «слабых сторон»;

- обоснование предложений по основным элементам комплексной оценки эффективности;

- прогноз перспектив внедрения предложенного модели.

Для определения критериев оценки эффективности обратимся к институциональным основам государственно-частного партнерства.

\section{Материалы и методы исследования}

Материалы и методы исследования: материалами исследования стали труды отечественных и зарубежных авторов, нормативная и 
статистическая информация в области ГЧП. В дальнейшем исследовании были применены методы логического анализа и синтеза, индукции и дедукции.

Основой разработки модели оценки эффективности должна, по нашему мнению, стать сущность ГЧП. В этой связи, определим государственно-частное партнерство как добровольное соглашение, заключенное между «государством» (публичный партнер) и частным хозяйствующим субъектом - «бизнесом» (частный партнер) на средне- или долгосрочный период и предполагающее разделение рисков, затрат и выгод в процессе создания и/или последующей эксплуатации общественно полезных объектов более [более подробно о проблеме формулировки определения ГЧП см. 5].

Ключевым аспектом ГЧП является добровольность участия в проекте (что особо важно для частного партнера) и взаимная экономическая заинтересованность. То есть, каждая из сторон преследует свои собственные цели (см. рис. 3), возможность реализации которых и определяет ее заинтересованность в успехе проекта [7].

\section{Государство}

(пуболичный парнер)

Основная цель: получение ожидаемого социальноэкономического эффекта

- привлечение дополнительных инвестиций в те сферы, которые традиционно относятся к сфере бюджетного финансирования (транспорт, здравоохранение, образование и т.д.);

- привлечение из частного сектора управленческих кадров, техники и технологии;

- привлечение из частного сектора управленческих кадров, техники и технологии

$$
\begin{gathered}
\text { Бизнес } \\
\text { (частный } \\
\text { партнер) }
\end{gathered}
$$

Основная цель: получение прибыли

- возможность выхода в сектор общественных услуг, на котором сушествует устойчивый спрос и который традиционно является монополией государства;

- реализация проектов, которые без участия государства не были бы привлекательными для инвестирования;

- разделение затрат и рисков с государством

Рис. 3. Основные цели и выгоды участия в ГЧП-проектах для государства и бизнеса. 
Оценивая эффективность ГЧП-проекта (как на предпроектной стадии, так и на стадии реализации и по окончании проекта) частный партнер в подавляющем большинстве случаев оценивает возможность получения прибыли, то есть, по сути, сравнивает результаты инвестирования в государственный или частный проект. [9, с. 29-30].

Государством, которое выступает инициаторам большинства проектов, оценка эффективности должна быть проведена на более ранней стадии (до презентации проекта) и по комплексной схеме, учитывающей необходимость учета как качественных, так и количественных показателей, как экономического, так и социального эффекта [14, pp. 241].

В существующей практике оценка эффективности ГЧП-проектов проходит в рамках обоснования способа реализации проекта и осуществляется уполномоченными органами в соответствии с Постановлением Правительства РФ от 30 декабря 2015 года № 1514 «О порядке проведения уполномоченным органом оценки эффективности проекта частного партнерства» [11].

В самом обобщенном виде эта процедура предполагает, что проект признается эффективным с экономической точки зрения, если чистая приведенная стоимость проекта больше или равна нулю [10, раздел 3 , п.14]. В последнем случае предполагается, что нулевая финансовая эффективность проекта компенсируется положительным социальным эффектом.

Социальная эффективность считается достаточной при выполнении двух условий: цели и задачи ГЧП-проекта соответствуют хотя бы одной цели (задаче) государственных (муниципальных) целевых программ в данной сфере; целевые показатели ГЧП-проекта соответствуют не менее чем двум целевым показателям государственных (муниципальных) целевых программ в данной сфере.

Кроме того, методика предполагает сопоставление выбранного способа реализации проекта с прямым государственным заказом [10].

По мнению ряда экспертов [4, 9] к настоящему времени стал очевиден ряд недостатков данной методики, в частности: формальный подход к сопоставлению вариантов государственно-частного 
партнерства и прямого государственного заказа; отсутствие рекомендаций по сопоставлению различных возможных вариантов ГЧПсоглашений (контракт жизненного цикла, концессия, инвестиционное соглашение и т.д.); недостаточность критериев качественного анализа социальных аспектов эффективности проектов.

\section{Результаты исследования и их обсуждение}

Учитывая перечисленные недостатки, представим далее авторские рекомендации по их устранению.

Следует подчеркнуть, что представленные ниже рекомендации носят теоретико-методологический характер, так как разработка конкретных показателей не может быть универсальна, так как требует соответствия сфере реализации проекта, его масштабам, срокам реализации и т.д.

Однако общие этапы и подходы к оценке эффективности могут и должны быть едиными, чтобы соответствовать целям ГЧП как одного из инструментов развития национальной экономики.

С нашей точки зрения оценка эффективности ГЧП-проекта может быть представлена как последовательность этапов:

Этап 1. Достижимость и целесообразность проекта

На этом этапе уполномоченным органам необходимо получить ответ на вопрос: достижимы ли цели, лежащие основе проекта в принципе?

Критериями оценки могут быть:

1. Соответствие целей (задач) ГЧП-проекта целям (задачам) государственной (муниципальной) политики на данный период;

2. Соответствие целей ГЧП-проекта ожиданиям граждан (может быть выявлено в ходе мониторинга общественного мнения или специального социологического исследования);

3. Наличие бюджетных средств для финансирования государственной доли обязательств по проекту;

4. Существование частных компаний с достаточными ресурсами для финансирования необходимой доли внебюджетных средств; 
5. Наличие в государственном и частном секторе требуемых специалистов, технологий, материальных ресурсов, которые могут быть привлечены к проекту.

На этом этапе отсеиваются: малозначимые или чрезмерно сложные проекты; проекты в отраслях/регионах с неясными перспективами; проекты, которые не будут поддержаны населением; проекты, для которых на данный момент отсутствуют необходимые интеллектуальные, технологические, материальные ресурсы и нет перспектив их получения.

\section{Этап 2. Сравнительная оценка эффективности ГЧП-проекта}

Если проект признан целесообразным и достижимым, необходимо получить ответ на следующие вопросы: 1) Целесообразно ли задействовать механизм ГЧП или проект может быть реализован посредством прямого государственного финансирования? 2) В каких формах ГЧП может быть реализован проект и какая из них наиболее целесообразна?

Этот этап наиболее полно представлен в существующей методике проведения оценки эффективности проектов ГЧП и МЧП [9] и основан на сопоставлении приведенных затрат и поступлений бюджетных средств с учетом рисков частного партнера (см. рис. 4).

\begin{tabular}{l} 
Риски \\
проектирования и \\
подготовительных \\
мероприятий \\
\hline \\
Расходы на \\
прединвестици- \\
онной стадии \\
проекта, в том \\
числе: расходы \\
на подготовку, \\
выкуп \\
земельного \\
участка для \\
размешения \\
объекта и т.д.
\end{tabular}

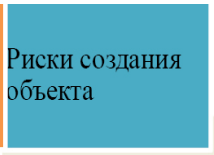

Расходы на строительство, реконструкцию, техническое перевооружение и т.д.

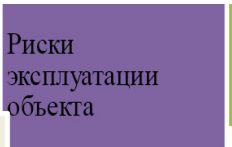

Расходы на эксплуатацию, техническое обслуживание и т.д.

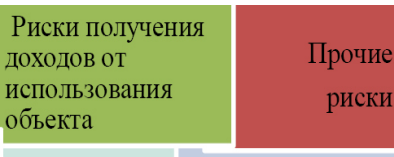

Выручка от оказания платных услуг населению
Расходы, связанные с возможной утратой объекта, политическими, социальными, экономическими событиями

Рис. 4. Виды рисков и соответствующие статьи расходов (поступлений) по проекту Источник: [9, с. 29-30] 
Общая схема оценки эффективности представлена на рис. 5.

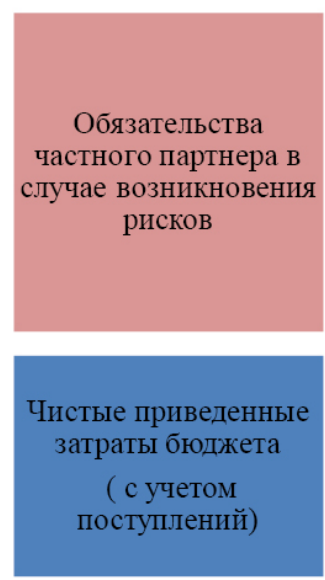

ГОССЗАКАЗ

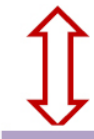

Сравнительное преимушество

Обязательства

публичного партнера

в случае

возникновения

рисков

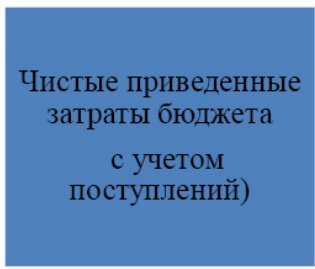

ГЧП

Рис. 5. Схема оценки сравнительной эффективности ГЧП-проектов

Ответ на второй вопрос может быть получен путем последовательного проведения:

1) юридической экспертизы проекта с целью уточнения, какие именно формы ГЧП-соглашений возможны в данном случае;

- экономической экспертизы (если юридически возможных форм две и более), предполагающей оценку рисков в случае применения каждой их форм (оценка может проводиться по аналогии с представленной выше методикой).

Этап 3. Оценка социальной эффективности

Этот этап является, по нашему мнению наиболее сложным, так как требует учета большого количества факторов, не все их из которых имеют количественную оценку.

На этом этапе государство (в лице уполномоченных органов) получает ответ на вопрос: Будет ли проект иметь социальный эффект?

В общем случае социальная эффективность проекта может быть выражена в следующих аспектах: 


\section{1. Общественная эффективность}

Будет ли реализация проекта прямо или косвенно способствовать реализации стратегических целей государственной политики, таких как:

- повышение уровня образования, квалификации, культурного развития населения;

- улучшение качества предоставляемых общественных благ;

- повышение уровня защищенности населения;

- рост уровня занятости и доходов населения;

- активизация бизнеса как в целом, так и по отдельным отраслям [14].

На этой стадии необходимо учитывать «комплексный положительный эффект», когда ГЧП-соглашения служат «маяком» государственной поддержки отрасли или региона, повышая их привлекательность для частных инвесторов.

2. Инфраструктурная эффективность

Этот аспект предполагает учет:

- потребности в объектах соответствующей инфраструктуры в отрасли/регионе;

- «кумулятивный эффект», который даст реализация данного проекта для других отраслей.

Сложность оценки инфраструктурной эффективности состоит в длительном периоде окупаемости большинства ГЧП-проектов, высоких первоначальных вложениях и длительном проявлении эффекта [более подробно см. 15, 16].

3. Инновационная эффективность:

В рамках данного аспекта необходимо определить:

- способствует ли проект взаимному дополнению и расширению сферы применения успешных достижений области технологии, управления, финансов между государственным и частным секторами экономики;

- способствует ли проект повышению доли инновационной продукции в отрасли/регионе.

4. Экологическая эффективность

В зависимости от сферы и масштаба ГЧП проекта показателями экологической эффективности могут быть: 
- сокращение объема выбросов;

- удаление экологически неблагополучных объектов (например, загруженных автомобильных дорог) от населенных пунктов;

- использовании новых, более экологичных технологий.

Очевидно, что при исследовании всех аспектов социальной эффективности ГЧП проектов необходимым будет использование экспертных оценок, сравнительного анализа уже реализованных проектов, мирровой и отечественной практики.

Этап 4. Итоговая оценка экономической эффективности

На этом этапе необходима детальная оценка экономической эффективности, результатом которой может быть корректировка отдельных условий проекта - срока реализации, долей участия государства и бизнеса, компенсаций и т.д.

В итоге уполномоченный государственный орган должен получить ответ на вопрос:

Как сделать проект не только соответствующим целям государственной политики, но интересным для участия частных партнеров?

Для проведения оценки целесообразно использовать классические показатели эффективности, которые можно разделить на три группы (см. рис 6) [более подробно см. 13].

Следует отметить, что представленная выше модель безусловно носит обобщенный характер, но, с нашей точки зрения, имеет как научно-теоретическую, так и практическую значимость, поскольку может быть использована в качестве:

- основы для дальнейшего развития правовой базы ГЧП, в части совершенствования методики оценки эффективности ГЧП проектов;

- алгоритма для разработки стратегии развития ГЧП в РФ, так как позволяет оценить различные аспекты эффективности проектов, и, следовательно, направления развития самого института ГЧП;

- рекомендации для прогнозирования эффективности ГЧП проектов на стадии инициации, так как предложенная модель позволяет оценить «привлекательность» проекта как для государства, так и для бизнеса. 


\section{Заключение}

Обобщая изложенное выше, можно сделать выводов:

1. Накопление информационной базы по практике ГЧП, увеличение числа вариантов ГЧП-соглашений, рост числа проектов и объемов привлеченных средств обусловливает необходимость развития подходов к оценке эффективности ГЧП-проектов.

2. Существующая методика оценки эффективности в целом позволяет сопоставить риски и выгоды ГЧП по сравнению с прямым бюджетным финансированием, а также оценки социальной эффективности, но не содержит механизмов сопоставления различных вариантов ГЧП-соглашений, а также оценки социальной эффективности.

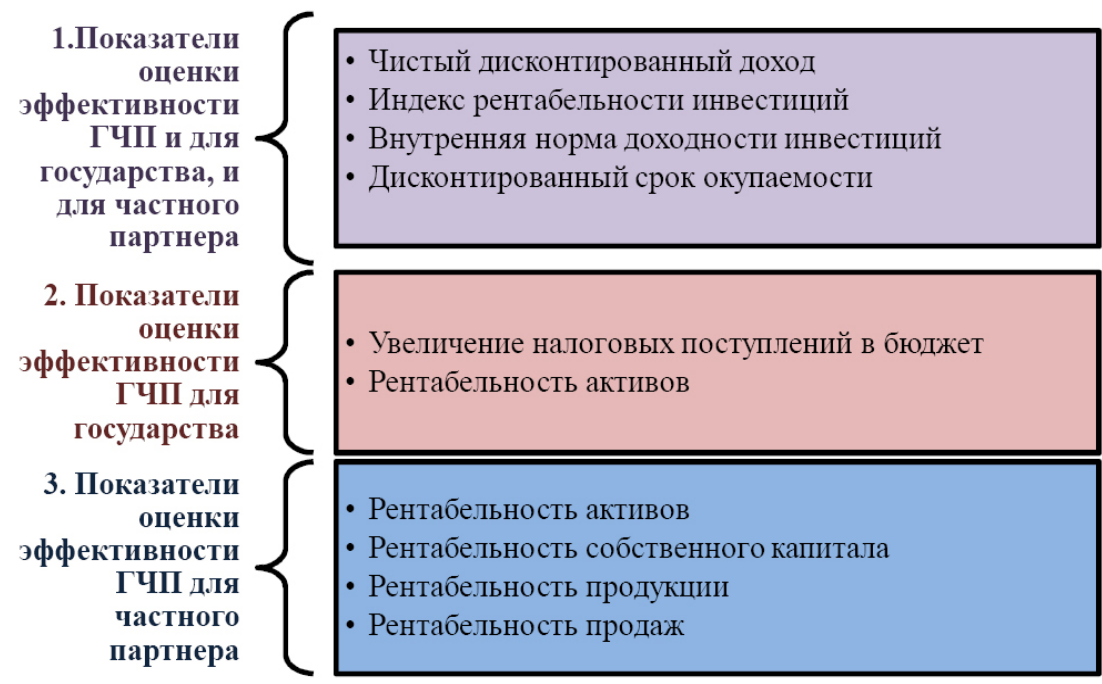

Рис. 6. Группы рекомендованных показателей для оценки итоговой экономической эффективности ГЧП-проекта

3. Предложенный авторами данного исследования механизм оценки, безусловно, является трудоемким. Однако следует учитывать, что прошедший все этапы оценки ГЧП-проект с большой степью вероятности будет отвечать не только задаче экономии бюджетных средств, но и стратегически целям государственной политики. 
4. Предложенный механизм ориентирован на то, чтобы учесть в окончательном варианте проекта интересы не только государства, но и бизнеса, что расширит круг потенциальных частных партнеров (например, при проведении конкурса), а также заинтересованность сторон в успешной реализации проекта.

5. Практическая значимость представленного исследования обусловлена тем, что авторская модель может стать основой для дальнейшего совершенствования законодательства в области ГЧП, разработки комплексной стратегии развития ГЧП в РФ, а также применяться как алгоритм обоснования необходимости реализации отдельных ГЧП-проектов их инициаторами.

\section{Список литературы}

1. Чернов Е.С. Государственно-частное партнерство в социально-экономическом развитии региона: дисс. .... канд. экон. наук. Краснодар, 2019.

2. Мажарова Л.А., Зенина Г.Д. Государственно-частное партнерство как инструмент развития национальной экономики // Экономика и предпринимательство. 2018. №2 (91). С. 459-463.

3. О государственно-частном партнерстве, муниципально-частном партнерстве в Российской Федерации и внесении изменений в отдельные законодательные акты Российской Федерации [Электронный ресурс]: федер. закон от 13.07.2015 № 224-Ф3 (в редакции от 26.07.2019). СПС КонсультантПлюс.

4. Оценка эффективности проектов ГЧП по сравнению с иными формами реализации инфраструктурных проектов в странах-участницах ЕАЭС: аналитическое исследование Национального центра ГЧП. Москва, 2018. 18 с.

5. Мажарова Л.А., Баркалов С.А., Санина Н.В. Анализ государственно-частного партнерства как специфического экономико-правового феномена. Вестник Воронежского государственного аграрного университета, 2017. № 2 (53). С. 143-147.

6. English L.M. Public Private Partnerships in Australia: an overview of their nature, purpose, incidence and oversight // UNSW Law Journal, 2006, no. 29(3), pp. 250-262. 
7. Сазонов В.Е. Государственно-частное партнерство в России и за рубежом: административно-правовое исследование: автореф. дис.... д-ра юрид. наук. Москва, 2013.

8. Кожевникова М.В. Организационно-экономический механизм развития инженерной инфраструктуры города на основе государственно-частного партнерства: дисс. ... канд. экон. наук. Санкт-Петербург, 2016.

9. Бахматова А.К. Проблемы оценки эффективности проекта государственно-частного партнерства // Вестник науки и образования. 2018. № 7(43). T.1. C. 29-30.

10. Методика оценки эффективности проекта государственно-частного партнерства, проекта муниципально-частного партнерства и определения их сравнительного преимущества [Электронный ресурс]: утверждена приказом Минэкономразвития России от 30.11.2015 № 894. СПС КонсультантПлюс.

11. О порядке проведения уполномоченным органом оценки эффективности проекта частного партнерства [Электронный ресурс]: постановление Правительства РФ от 30 декабря 2015 года № 1514. СПС КонсультантПлюс.

12.Zheng J., Roehrich J.K., Lewis M.A. The dynamics of contractual and relational governance: Evidence from long-term public-private procurement arrangements. Journal of Purchasing and Supply Management, 2008, no. 14(10), pp. 43-54.

13. Public-Private Partnerships Reference Guide. International Bank for Reconstruction and Development. The World Bank, Asian Development Bank, and Inter-American Development Bank, 2014, pp. 6, 31-32.

14. Ranga M., Etzkowitz H. Triple Helix Systems: An Analytical Framework for Innovation Policy and Practice in the Knowledge Society // Human Sciences and Technology Advanced Research Institute (H- STAR), 2013, pp. 237-262.

15. Баркалов С.А., Мажарова Л.А. ГЧП в социальной сфере: проблема выбора эффективной модели // Экономика и менеджмент систем управления: научно-практический журнал. 2018. № 4(30). С. 4-10.

16. Mazharova L.A., Agafonova M.S., Stroganova Ya.S., Shevchenko L.V. Development of the methodology of effectiveness of public-private partnership projects. Espacios, 2018, no. 1, T. 39, pp.24. 


\section{References}

1. Chernov E.S. Gosudarstvenno-chastnoe partnerstvo v social'no-jekonomicheskom razvitii regiona [Public-private partnership in the socio-economic development of the region]: diss. ... kand. jekon. nauk. Krasnodar, 2019.

2. Mazharova L.A., Zenina G.D. Gosudarstvenno-chastnoe partnerstvo kak instrument razvitija nacional'noj jekonomiki [Public-private partnership as a tool for the development of the national economy]. Economy and business. 2018. №2 (91), pp. 459-463.

3. O gosudarstvenno-chastnom partnerstve, municipal'no-chastnom partnerstve v Rossijskoj Federacii i vnesenii izmenenij v otdel'nye zakonodatel'nye akty Rossijskoj Federacii [About public-private partnership, municipal-private partnership in the Russian Federation and amendments to certain legislative acts of the Russian Federation]. SPS Konsul 'tantPljus.

4. Ocenka jeffektivnosti proektov GChP po sravneniju s inymi formami realizacii infrastrukturnyh proektov $v$ stranah-uchastnicah EAJeS: analiticheskoe issledovanie Nacional'nogo centra GChP [Assessment of the effectiveness of PPP projects in comparison with other forms of implementation of infrastructure projects in the EEU member States: an analytical study of the central PPP center]. Moscow, 2018. 18 p.

5. Mazharova L.A., Barkalov S.A., Sanina N.V. Analiz gosudarstvenno-chastnogo partnerstva kak specificheskogo jekonomiko-pravovogo fenomena [Analysis of public-private partnership as a specific economic and legal phenomenon]. Vestnik Voronezhskogo gosudarstvennogo agrarnogo universiteta [Bulletin of the Voronezh state agrarian University], 2017. № 2 (53), pp. 143-147.

6. English L.M. Public Private Partnerships in Australia: an overview of their nature, purpose, incidence and oversight. UNSW Law Journal, 2006, № 29(3), pp. 250-262.

7. Sazonov V.E. Gosudarstvenno-chastnoe partnerstvo v Rossii i za rubezhom: administrativno-pravovoe issledovanie [Public-private partnership in Russia and abroad: administrative and legal research]. Moscow, 2013.

8. Kozhevnikova M.V. Organizacionno-jekonomicheskij mehanizm razvitija inzhenernoj infrastruktury goroda na osnove gosudarstvenno-chastnogo partnerstva [Organizational and economic mechanism for the develop- 
ment of the city's engineering infrastructure on the basis of public-private partnership]. Sankt-Peterburg, 2016.

9. Bahmatova A.K. Problemy ocenki jeffektivnosti proekta gosudarstvenno-chastnogo partnerstva [Problems of evaluating the effectiveness of a public-private partnership project]. Vestnik nauki i obrazovaniya [Bulletin of science and education], 2018, № 7(43). V.1, pp. 29-30.

10. Metodika ocenki jeffektivnosti proekta gosudarstvenno-chastnogo partnerstva, proekta municipal'no-chastnogo partnerstva i opredelenija ih sravnitel'nogo preimushhestva [Methodology for evaluating the effectiveness of a public-private partnership project, a municipal-private partnership project, and determining their comparative advantage] utverzhena prikazom Minjekonomrazvitija Rossii ot 30.11.2015 № 894. SPS Konsul'tantPljus.

11. O porjadke provedenija upolnomochennym organom ocenki jeffektivnosti proekta chastnogo partnerstva [About the procedure for the authorized body to evaluate the effectiveness of a private partnership project]: postanovlenie Pravitel'stva RF ot 30 dekabrja 2015 goda № 1514. SPS Konsul'tantPljus.

12.Zheng J., Roehrich J.K., Lewis M.A. The dynamics of contractual and relational governance: Evidence from long-term public-private procurement arrangements. Journal of Purchasing and Supply Management, 2008, no. 14(1), pp. 43-54.

13. Public-Private Partnerships Reference Guide. International Bank for Reconstruction and Development. The World Bank, Asian Development Bank, and Inter-American Development Bank, 2014, pp. 6, 31-32.

14. Ranga M., Etzkowitz H. Triple Helix Systems: An Analytical Framework for Innovation Policy and Practice in the Knowledge Society. Human Sciences and Technology Advanced Research Institute (H- STAR), 2013, pp. 237-262.

15. Barkalov S.A., Mazharova L.A. GChP v social'noj sfere: problema vybora jeffektivnoj modeli [PPP in the social sphere: the problem of choosing an effective model]. Ekonomika i menedzhment sistem upravleniya [Economics and management of management systems], 2018, № 4(30), pp. 4-10. 
16. Mazharova L.A., Agafonova M.S., Stroganova Ya.S., Shevchenko L.V. Development of the methodology of effectiveness of public-private partnership projects. Espacios, 2018, № 1, V.39. P. 24.

\section{ДАННЫЕ ОБ АВТОРЕ}

Мажарова Лина Александровна, доцент кафедры экономки и управления недвижимостью, кандидат экономических наук, доцент ФГБОУВО «Российский государственный университет правосудия»

ул. Новочерёмушкинская, 69, г. Москва, 117418, Российская Федеращия

linamazharova@yandex.ru

\section{DATA ABOUT THE AUTHOR}

Mazharova Lina Alexandrovna, Associate Professor at the Department of Economics and Real Estate Management, Candidate of Economics Sciences, Associate Professor Russian State University of Justice 69, Novocheromushkinskaya str., Moscow, 117418, Russian Federation

linamazharova@yandex.ru 